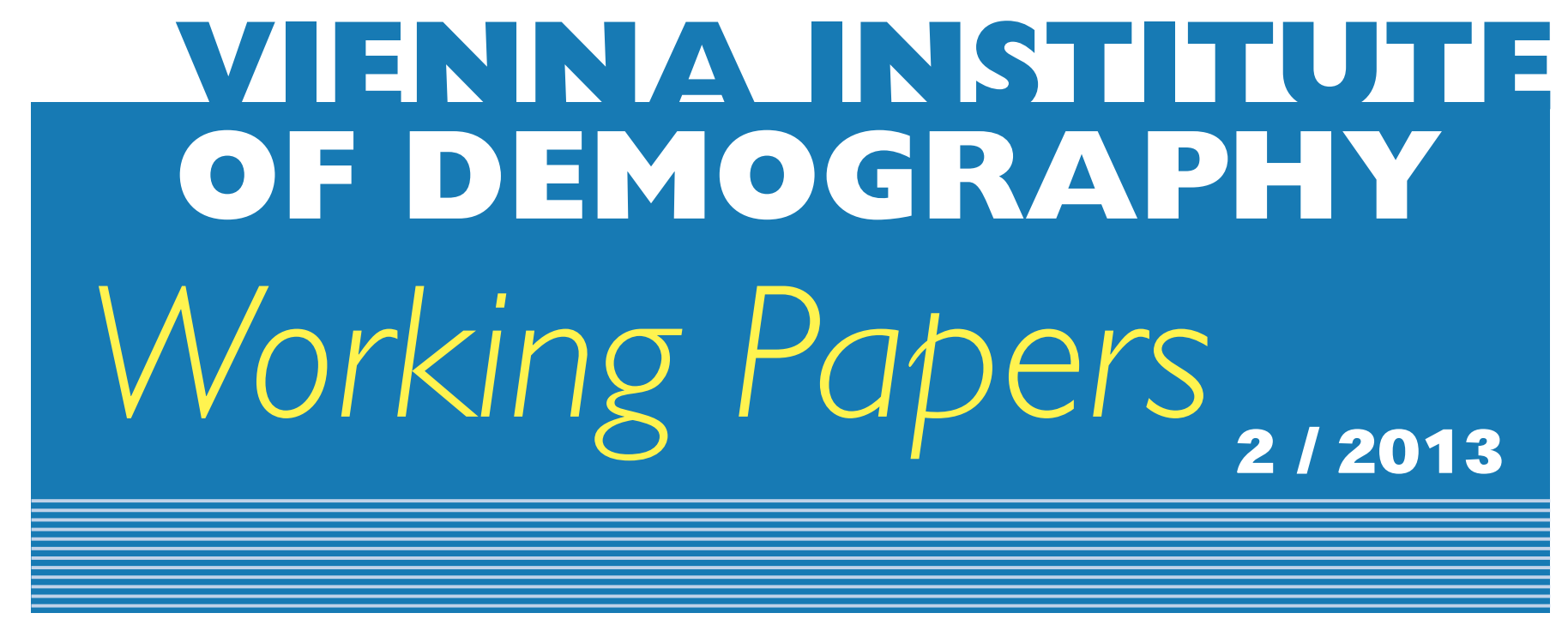

Gustav Feichtinger, Alexia Prskawetz, Andrea Seidl, Christa Simon and Stefan Wrzaczek

\title{
Do Egalitarian Societies Boost Fertility?
}

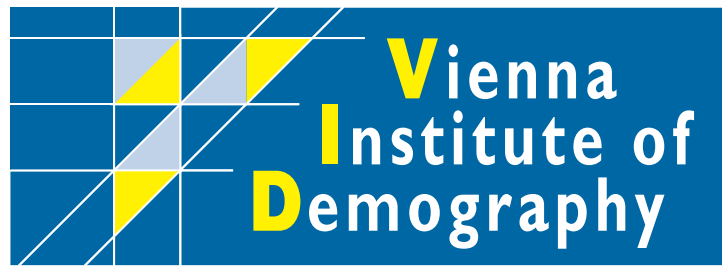

Vienna Institute of Demography Austrian Academy of Sciences

Wohllebengasse I2-14

A-1040Vienna $\cdot$ Austria

E-Mail:vid@oeaw.ac.at

Website: www.oeaw.ac.at/vid 


\begin{abstract}
In general, the spreading of egalitarian family values has often been associated with a decline in fertility. However, recently a rebound in fertility has been observed in several industrialized countries. A possible explanation of this trend may be the spread of egalitarian values that induced institutional changes - such as expansion of child care facilities and father leave - fostering the combination of parenthood and the egalitarian lifestyle. In our paper we build up a formal model to study the diffusion from traditional to egalitarian gender-behavior and its impact on fertility. We find that the long-run development of the total fertility within a population not only depends on the pace of diffusion of egalitarianism and the extent to which social interactions affect the egalitarians' birth rates, but also on the initial number of traditionalists and egalitarians. We show under which conditions a fertility decline is followed by a subsequent recovery.
\end{abstract}

\title{
Keywords
}

Egalitarianism, family models, diffusion, fertility.

\section{Authors}

Gustav Feichtinger, Wittgenstein Centre (IIASA, VID/ÖAW, WU), Vienna Institute of Demography/Austrian Academy of Sciences, and Vienna University of Technology, Institute for Mathematical Methods in Economics. Email: gustav@eos.tuwien.ac.at

Alexia Prskawetz, Wittgenstein Centre (IIASA, VID/ÖAW, WU), Vienna Institute of Demography/Austrian Academy of Sciences and Vienna University of Technology, Institute for Mathematical Methods in Economics. Email: afp@econ.tuwien.ac.at

Andrea Seidl, Wittgenstein Centre (IIASA, VID/ÖAW, WU), Vienna Institute of Demography/Austrian Academy of Sciences and Vienna University of Technology, Institute for Mathematical Methods in Economics. Email: andrea.seidl@tuwien.ac.at

Christa Simon, Vienna University of Technology, Institute for Mathematical Methods in Economics. Email: christa.simon@tuwien.ac.at

Stefan Wrzaczek, University of Vienna, Department of Business Administration and Vienna University of Technology, Institute for Mathematical Methods in Economics. Email: stefan.wrzaczek@tuwien.ac.at

\section{Acknowledgements}

This research was supported by the Austrian Science Fund (FWF) under Grants P20408G14, P24125-N13 and P25275. 


\section{Do Egalitarian Societies Boost Fertility?}

Gustav Feichtinger, Alexia Prskawetz, Andrea Seidl, Christa Simon, and Stefan Wrzaczek

\section{Introduction}

During the last decades most industrialised countries have faced fertility rates below the replacement level. The decline of fertility has often been associated with a rise in economic development. However, in recent years the relationship between fertility and human development has changed fundamentally and as a consequence a rebound in fertility is being observed in many industrialised countries, see e.g. Myrskylä et al. (2009).

Esping-Andersen and Billari (2012) try to explain this phenomenon by a stronger support of gender equality in societies caused by a higher degree of diffusion of modern family values. In particular they consider a society which consists of two types of families: traditional and egalitarian. See e.g. Davis and Greenstein (2009) for a general discussion on characteristics by which one can identify the two population groups. In particular, Esping-Andersen et al. (2012) define an egalitarian couple by an equal share of the men's and women's domestic and paid work.

The adoption of more egalitarian family values which has been observed in the past decades in many countries lead to fundamental changes in society, see e.g. EspingAndersen (2009); compare also Ciabattari (2001) who studies cohort and period effects on changes in men's attidudes towards egalitarianism. A shift was observed from the classical male-breadwinner family to family models where both partners work. Such a development is in general associated with a continuing decline in fertility. McDonald (2000) argues that the fertility transition from high to low fertility as observed in many advanced countries is accompanied by an increased gender equity within families and a conflict between individual aspirations and the expected role of women within the family.

However, as already mentioned, in several industrialised countries with a high degree of gender equity fertility has risen again. A reason for this might be a higher support of combining parenthood and work through measures like the possibility of father leaves, the option to work from home, allowing flexible working hours, as well as the expansion of child care facilities. Indeed, McDonald (2013) observes that fertility is lower in countries where support for the combination of work and family is not provided. Aassve et al. (2012) argue that trust into institutions plays a key role regarding fertility trends as it allows outsourcing of traditional family activities to support the combination of parenthood and female labour force participation. 
Torr and Short (2004) report that the probability of a second birth is higher for both egalitarian and traditionalist couples than for couples in between those family models. This might indicate that when it is only possible to partially adopt an egalitarian lifestyle, because the lifestyle is not supported by policy measures, fertility will suffer.

The present paper extends the approach of Esping-Andersen and Billari (2012) by explicitly modelling the dependence of the birth rate of the egalitarians on their number. This endogenization of the birth rate of the egalitarians accounts for the fact that there is a feedback from the birth rate to the size of the subgroup and vice-versa. We also relax the assumption of a fixed-size population, leading to the study of a two-dimensional dynamic system.

The birth rate of a population at a given time is the weighted mean of the subpopulationspecific birth rates, where the weights are the population size in each subgroup. A model which is able to endogenize the fertility behavior of the egalitarians gives a richer picture of the population processes. The number of egalitarians may therefore either increase through the exogenous diffusion process, being an indicator of development of family values within the society, or alternatively by its own birth rate.

A key factor in the transition from a traditional to an egalitarian society are social interactions. As such the dynamic model we consider in the present paper fits in the class of diffusion models which play an important role for a large number of applications. The basic motivation of such models is to gain insights about how and why an innovation, which can be a product, a practice or an idea, like in our model, spreads over time among the members of a social system, see Casterline (2001); Rogers (2003).

Similar to Lopez-Pintado and Watts (2008), we study a dynamic model where social influences drive the behaviour of heterogeneous individuals in the society, here with respect to fertility. Lopez-Pintado and Watts (2008) explicitly model the decision of the agents depending on a threshold which gives the number of people that must exist in the population so that the agent changes his or her behaviour. They distinguish three different ways in which activities of others can influence the behaviour of an agent: positive, negative and non-monotonic externalities arising through social interactions. If positive externalities are assumed, then the agent changes his or her behaviour if the fraction of the population who already started to act in that way is higher than the agent-specific threshold. This means that the society has a positive impact on the individuals' decisions. If negative externalities are assumed, adoption is more attractive if the fraction of adopters within the society is low. In case of non-monotonic externalities, a positive impact on the individuals' decisions is given if the number is neither too low nor too high, depending on the threshold. In our model, we account for the externality by involving the state-dependent diffusion term and the dependence of the birth rate on the number of egalitarians themselves.

With this model we are able to replicate and extend the results of Esping-Andersen and Billari (2012), by showing that a rebound in fertility may occur. We also explain in detail what drives the U-shaped path of total fertility over time. We find that the U-shaped time path of fertility is driven by parameter constellations which reflect the case where traditionalists change their family values faster than their fertility behaviour. In 


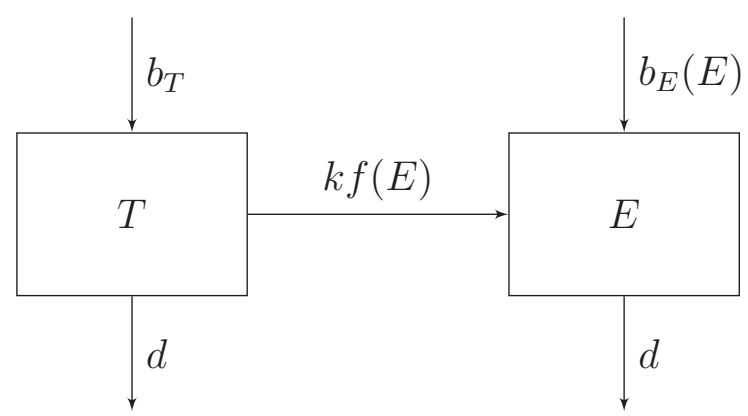

Figure 1: Flow diagram; $b_{T}$ and $b_{E}(E)$ denote the birth rates of the traditionalists and the egalitarians, respectively, $d$ is the death rate, $f(E)$ the initiation function and $k$ denotes the pace of diffusion.

fact, this time lack may happen due to initial insufficient support in family policy in the society.

The remaining paper is structured as follows. In Section 2 we present the model. We analyse the model and its implication in detail analytically in Section 3 and numerically in Section 4. Section 5 concludes.

\section{The Model}

We consider a dynamic system consisting of two state variables, $T(t)$ denotes the number of traditionalists at time $t$, and $E(t)$ the number of egalitarians. ${ }^{1}$ Figure 1 shows that into each of these groups there is an inflow resulting from births and an outflow resulting from deaths. Moreover, there is a flow from $T$ to $E$ which relates to the number of traditionalists who adopt egalitarian family values.

The birth rate of the traditionalists $b_{T}$ is assumed to be constant, while the birth rate of the egalitarians $b_{E}(E)$ positively depends on the number of egalitarians itself. The underlying assumption is that an increasing number of egalitarians implies a higher acceptance rate of their lifestyle (through social interactions, etc.) within the overall population. Consequently, policies facilitating equal task sharing within couples (e.g. father leaves, flexible working hours) or combining motherhood and career (such as providing comprehensive child care, the possibility to work from home) are in higher demand and may be more likely to be implemented, thereby making larger families more attractive. The dependence of the birth rate on $E$ also reflects an implicitly assumed heterogeneity within the population: when egalitarianism is seen as a real obstacle towards a large family due to its low social acceptance, only women with a high preference towards the associated goals like good education, career or income will adopt this lifestyle at the expense of a large number of children.

When egalitarianism is widely accepted, then also people with a higher preference

\footnotetext{
${ }^{1}$ In the subsequent discussion we omit time argument $t$.
} 


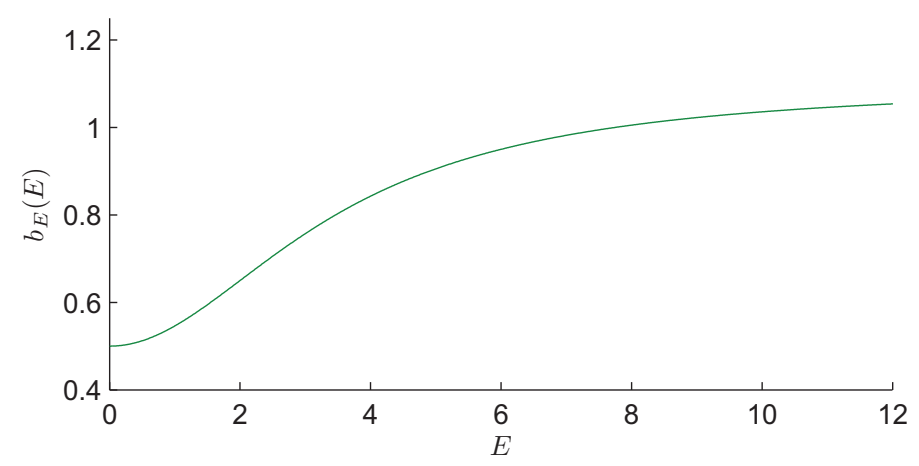

Figure 2: S-shaped birth rates depending on the number of egalitarians.

for offspring will adopt these family values. In particular we consider a convex-concave (S-shaped) shape of the birth rate related to the number of egalitarians, see Figure 2. When there are only a few egalitarians this lifestyle finds little support in terms of available measures to facilitate motherhood, consequently birth rates will be low. However, the positive effect of such measures on the birth rate is limited and as such birth rates will not increase beyond a certain threshold even when there is strong support of egalitarian families. As such we have

$$
b_{E}(E)=\nu+\beta \frac{E^{2}}{E^{2}+m},
$$

where $\nu$ is the birth rate of egalitarians independent of social interactions and parameters $\beta$ and $m$ describe the impact of social interactions on the birth rate. In particular $\beta$ measures the height of the S-shaped part of the function, and $m$ the steepness. Note that in line with the literature, see e.g. Davis and Greenstein (2009), we assume that children initially adopt the lifestyle of their parents (but of course might change their attitudes due to peer influence later on). An important assumption within our model is that the constant birth rate of traditionalists is higher than just replacement fertility level $\left(b_{T}>d\right)$, i.e. if the population consists only of traditionalists it will grow in the long run. We further assume that if the share of egalitarians is small within the population, their birth rate is smaller than the death rate $\left(b_{E}(0)=\nu<d\right)$. Without these assumptions it is not possible (except for the hairline case $b_{T}=d$ and $b_{E}(E)=d$ for $\left.0 \leq E \leq \infty\right)$ to study scenarios where the population converges towards a stable level, i.e. the population would always either explode or become extinct in the long run.

There is a flow from traditionalists to egalitarians. This diffusion process of family values is positively influenced by the number of egalitarians, meaning that the incentive to adopt an egalitarian lifestyle is higher when there are many egalitarians. The reason for this is the wider acceptance of this family model and the resulting higher degree of implemented support measures. We also consider an S-shaped function $f(E)$ describing the influence of egalitarians on the number of traditionalists who adopt an egalitarian lifestyle, i.e.

$$
f(E)=a_{E}+\alpha \frac{E^{2}}{E^{2}+n} .
$$

Parameter $a_{E}$ denotes the fraction of traditionalists who become egalitarians without being influenced by anyone else. Parameters $\alpha$ and $n$ measure the impact of social interactions on the diffusion, where $\alpha$ relates to the height and $n$ to the steepness of the function. 
Consequently, the state equations ${ }^{2}$ are

$$
\begin{aligned}
& \dot{T}=\left(b_{T}-d\right) T-k f(E) T, \\
& \dot{E}=\left(b_{E}(E)-d\right) E+k f(E) T,
\end{aligned}
$$

where parameter $k$ describes the pace of diffusion and $d$ denotes the death rate.

\section{Analytical Results}

In the long run the population size can either explode, fluctuate or reach a constant value. For the latter case, we study steady states and their stability properties by evaluating the Jacobian matrix

$$
J(T, E)=\left(\begin{array}{cc}
b_{T}-d-k f(E) & -k f^{\prime}(E) T \\
k f(E) & b_{E}(E)+b_{E}^{\prime}(E) E-d+k f^{\prime}(E) T
\end{array}\right),
$$

at the steady state in the subsequent discussion.

In a steady state it has to hold that births within a population must not exceed deaths and vice versa. As such,

$$
b_{T} T+b_{E}(E) E=d(T+E) .
$$

Due to the assumption $b_{T}>d$ in a steady state it has to hold that the birth rate of the egalitarians at a steady state $(\hat{T}, \hat{E})$ is below or equal to replacement fertility level, i.e.

$$
b_{E}(\hat{E}) \leq d
$$

\subsection{Interior Steady State with $\hat{T}>0$ and $\hat{E}>0$}

From equation (3), we conclude that at an interior steady state it has to hold that $b_{T}-$ $d-k f(\hat{E})=0$. Together with equation (2), we obtain the steady state value of $E$ :

$$
\hat{E}=\sqrt{\frac{Y n}{1-Y}}, \quad \text { with } Y=\frac{b_{T}-d-k a_{E}}{\alpha k} .
$$

Applying equation (6) we obtain

$$
\hat{T}=\hat{E} \frac{b_{E}(\hat{E})-d}{d-b_{T}}
$$

Consequently, the interior steady state is unique.

\footnotetext{
${ }^{2}$ As usual, the denotation with dots refers to the time derivative, i.e. $\dot{T}=\frac{\mathrm{d} T}{\mathrm{~d} t}$ and $\dot{E}=\frac{\mathrm{d} E}{\mathrm{~d} t}$.
} 
The interior steady state is only admissible if $0<Y<1$, which implies the following restriction on the parameter set

$$
k a_{E}<b_{T}-d<k\left(\alpha+a_{E}\right) .
$$

The above inequality states that the natural rate of increase of the traditionalists is bounded from below by the lowest possible rate of diffusion and from above by the highest level of diffusion. For a lower rate of natural increase the subpopulation of traditionalists would vanish and for a higher one it would explode.

We know that for an interior steady state $(\hat{T}, \hat{E})$ with $\hat{T}>0$ it has to hold that $b_{T}-d-k f(\hat{E})=0$. Consequently, evaluating the Jacobian matrix (5) at this steady state, we find

$$
\operatorname{det} J(\hat{T}, E)=k^{2} f(\hat{E}) f^{\prime}(\hat{E}) \geq 0,
$$

and

$$
\operatorname{tr} J(\hat{T}, \hat{E})=b_{E}(\hat{E})+b_{E}^{\prime}(\hat{E}) \hat{E}-d+k f^{\prime}(\hat{E}) \hat{T} .
$$

Due to the non-negativity of the determinant of the Jacobian of the interior steady state we can exclude that this steady state is a saddle point (see e.g. Grass et al. 2008). Furthermore, the steady state can only be stable if the trace of its Jacobian is negative which requires the following conditions to hold:

$$
b_{E}(\hat{E})<d \quad \text { and } \quad d \geq b_{E}(\hat{E})+b_{E}^{\prime}(\hat{E}) \hat{E}+k f^{\prime}(\hat{E}) \hat{T} .
$$

\subsection{Boundary Steady States}

The assumption that the birth rate of the traditionalists exceeds the death rate $\left(b_{T}>d\right)$, implies that we can exclude the boundary steady state where the population consists only of traditionalists with $\hat{E}=0$ and $\hat{T}>0$.

However, there can be a steady state where the population consists only of egalitarians. At this steady state it has to hold that $b_{E}\left(\hat{E}_{B}\right)=d$, which can be rewritten using (1) as

$$
\nu+\beta \frac{E(t)^{2}}{E(t)^{2}+m}-d=0 .
$$

Consequently,

$$
\hat{T}_{B}=0, \hat{E}_{B}=\sqrt{\frac{X m}{(1-X)}}, \quad \text { with } X=\frac{d-\nu}{\beta} \text {. }
$$

This steady state is only admissible if

$$
0 \leq d-\nu \leq \beta,
$$


implying that the exogenous part of the egalitarians' birth rate (which is independent of the number of egalitarians) must be smaller than the death rate, otherwise the number of egalitarians would grow infinitely. On the other hand, the total birth rate of egalitarians, which converges for large $E$ towards $\nu+\beta$, must be equal or larger than the death rate for a high number of egalitarians. This condition guarantees that the number of egalitarians will not necessarily decrease to zero.

For the boundary steady state $\left(\hat{T}_{B}, \hat{E}_{B}\right)$ where it holds that $b_{E}\left(\hat{E}_{B}\right)=d$, the determinant and the trace of the Jacobian are given as follows

$$
\operatorname{det} J\left(0, \hat{E}_{B}\right)=\left(b_{T}-d-k f\left(\hat{E}_{B}\right)\right) b_{E}^{\prime}\left(\hat{E}_{B}\right) \hat{E}_{B}
$$

and

$$
\operatorname{tr} J\left(0, \hat{E}_{B}\right)=b_{T}-d-k f\left(\hat{E}_{B}\right)+b_{E}^{\prime}\left(\hat{E}_{B}\right) \hat{E}_{B}
$$

Consequently, since $b_{E}^{\prime}\left(\hat{E}_{B}\right) \geq 0$ the steady state is a saddle point if the determinant of the Jacobian evaluated at this steady state is negative, which holds if

$$
b_{T}-d-k f\left(\hat{E}_{B}\right)<0 .
$$

The boundary steady state is unstable if the trace of the Jacobian is positive, which implies

$$
b_{T}-d-k f\left(\hat{E}_{B}\right)>0 .
$$

Consequently, we can exclude that $\operatorname{det} J\left(0, \hat{E}_{B}\right) \geq 0$ and $\operatorname{tr} J\left(0, \hat{E}_{B}\right) \leq 0$ at the same time, and as such that the boundary steady state is stable.

The last possibility for a boundary steady state is that birth rates are so small that the population gets extinct in the long run with

$$
\hat{T}_{0}=0, \hat{E}_{0}=0
$$

Considering the determinant of the Jacobian, which is

$$
\operatorname{det} J(0,0)=-\left(b_{T}-d\right) d \leq 0,
$$

we see that this steady state is always a saddle point for $b_{T}>d$. The eigenvalues and corresponding eigenvectors are $\xi_{1}=b_{T}-d, \sigma_{1}=\left(\begin{array}{l}1 \\ 0\end{array}\right)$ and $\xi_{2}=-d, \sigma_{2}=\left(\begin{array}{l}0 \\ 1\end{array}\right)$, implying that this steady state can only be approached if $T(0)=0$. This steady state and the boundary steady state $\left(\hat{T}_{B}, \hat{E}_{B}\right)$ coincide for $\nu=d$.

Concluding, in the previous section we were able to see that depending on the pa- 


\begin{tabular}{|c|c|c|c|c|c|c|c|c|}
\hline$b_{T}$ & $\nu$ & $d$ & $m$ & $a_{E}$ & $\alpha$ & $n$ & $k$ & $\beta$ \\
\hline 1.1 & 0.5 & 1 & 12 & 0.01 & 1 & 0.5 & 0.4 & 0.6 \\
\hline
\end{tabular}

Table 1: Parameters for the numeric calculations

rameters there are at most three steady states which might determine the long-run development of traditionalists and egalitarians. In order to study the transient behaviour of solution paths and birth rates over time in more detail we have to resort to numerical calculations.

\section{$4 \quad$ Numerical Results}

The main focus of our paper is to study the underlying mechanism in the diffusion of family values. We estimate our basic parameters in a manner that we can explain the observed rebound in fertility caused by higher support of egalitarian lifestyle as described in Esping-Andersen and Billari (2012).

Note, however, that the birth rates we use are based on empirical evidence. In a recent survey article by Davis and Greenstein (2009), it was observed that while women with higher education and/or employment are more likely to adopt an egalitarian lifestyle due to a higher exposure to the underlying ideas, people with increased levels of religious practice are more in favour of traditionalism. Thus we use education and religion as indication of the lifestyle. The birth rate for traditionalists is the birth rate observed for women with the lowest degree of education in Austria in 2008/09 within the Generations and Gender Survey, see Buber and Neuwirth (2009).

To find a reference point for the birth rate of egalitarians independent of the influence of other egalitarians was more difficult as such data is practically not observable. The birth rates of both highly educated women as well as non-religious women in Austria is around 1.3 (which would translate to 0.65 in our one-sex model), see Buber and Neuwirth (2009). This means that $\nu$ should be below this value. In order not to take a value which is too low for this parameter, we considered the lowest observed fertility rates (see e.g. Conrad et al. 1996; Billari and Kohler 2004) as some kind of threshold.

In the following we will first discuss in detail a scenario where we can observe a rebound in fertility. The parameters we use for the numerical calculation can be found in Table 1.

\subsection{A Rebound of Fertility}

An example how the birth rate within a population might develop in a U-shaped manner (as described by Esping-Andersen and Billari 2012) can be found in Figure 3. Correspondingly, we can observe in Figure 4 how the number of traditionalists and egalitarians will develop if the initial number of traditionalists $T_{0}$ is relatively high compared to the initial 


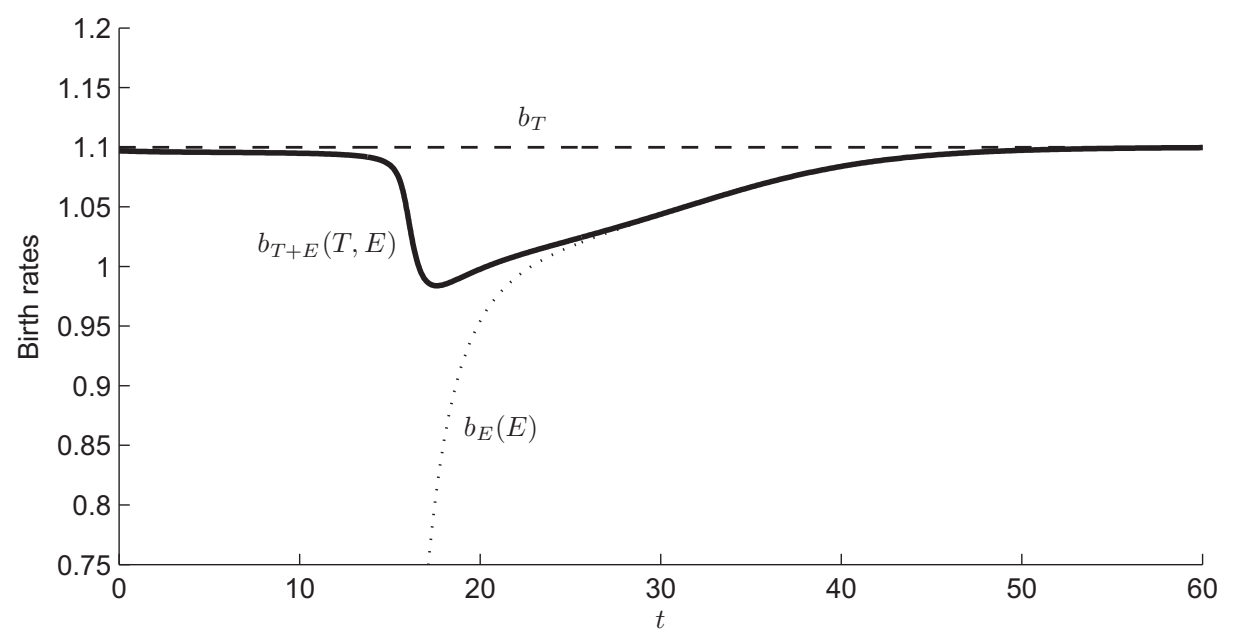

Figure 3: Development of birth rates over time for $k=0.4, \beta=0.6$. $b_{T+E}$ denotes the weighted mean of the birth rates. The initial number of traditionalists $\left(T_{0}=2\right)$ exceeds the initial number of egalitarians $\left(E_{0}=0.01\right)$.

number of egalitarians $E_{0}$. First the number of traditionalists rises due to their high birth rate. Only very few members of this subpopulation group adopt an egalitarian lifestyle due to missing incentives to do so. Yet, the number of egalitarians will very slowly start to increase. In this early stage of the diffusion process, the rise of egalitarianism is mainly driven by people who adopt this lifestyle independently of others.

As the total population size increases, more and more people become egalitarian, meaning that more traditionalists become exposed to the new family model and have a higher incentive to adopt it. Consequently, $T$ will fall. While it is attractive to join the $E$-subpopulation and thus their share within the total population gets bigger and bigger (see Figure 5), the impact of the number of egalitarians on the birth rates is not particular strong yet (e.g. due to a lack of support by policy measures); as a consequence the birth rate of the total population falls. However, when $E$ increases so does the birth rate of the egalitarians. Due to their increasing number the birth rate of the total population rises too. This growth, however, is limited and while the total population will grow in size as births exceed deaths, birth rates will converge towards a stable level.

In the right panel of Figure 4 we can see the corresponding phase portrait. The black line with the arrow depicts the described solution path. We can see that in this scenario there are three admissible steady states which influence the development of the two subpopulation groups. The interior steady state $(\hat{T}, \hat{E})=(1.96,0.4)$ is an unstable focus, while the boundary steady state with $\left(\hat{T}_{B}, \hat{E}_{B}\right)=(0,7.75)$ is a saddle point. The boundary steady state $\left(\hat{T}_{0}, \hat{E}_{0}\right)=(0,0)$ is also a saddle point. The dotted lines depict the isoclines. Below the $\dot{T}=0$ isocline, $T$ always increases and, of course, above it $T$ always decreases. On the left side of the $\dot{E}=0$ isocline, the number of egalitarians increases, on the right side it decreases. The line connecting the two steady states $(\hat{T}, \hat{E})$ and $\left(\hat{T}_{B}, \hat{E}_{B}\right)$ is the one-dimensional stable manifold of the boundary steady state. If the initial state value lies below this line the number of traditionalists and egalitarians might first fluctuate before $T$ decreases and $E$ increases in the long run. 

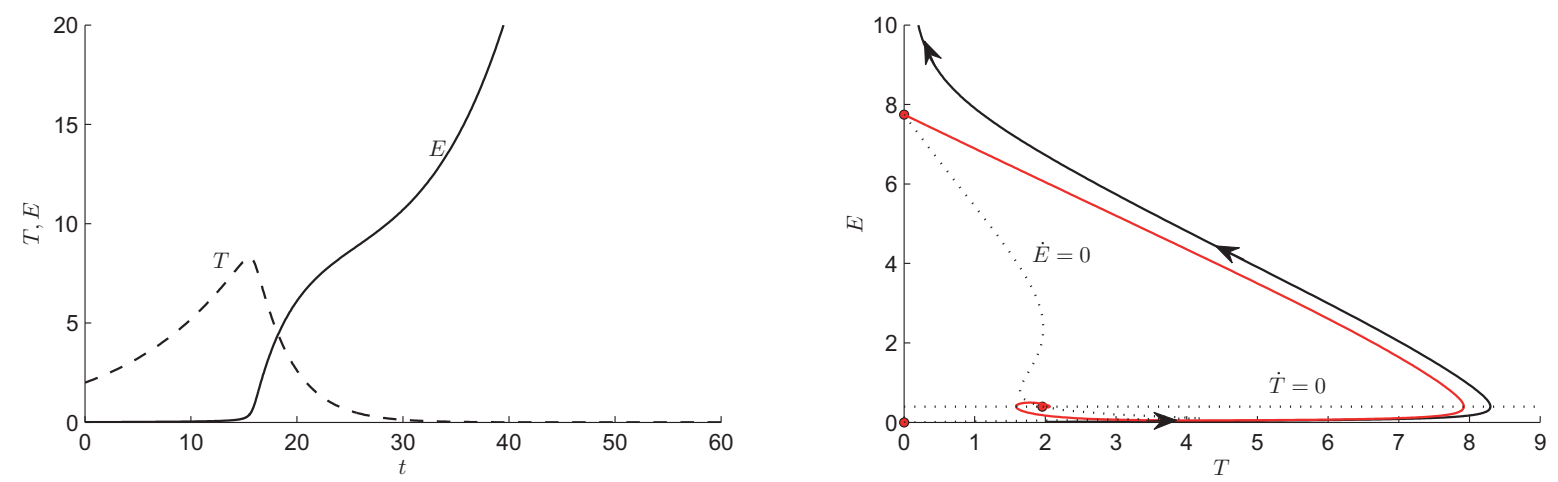

Figure 4: Time path (left panel) and phase portrait (right panel) showing the development of the number of traditionalists and egalitarians over time for $T_{0}=2, E_{0}=0.01$.

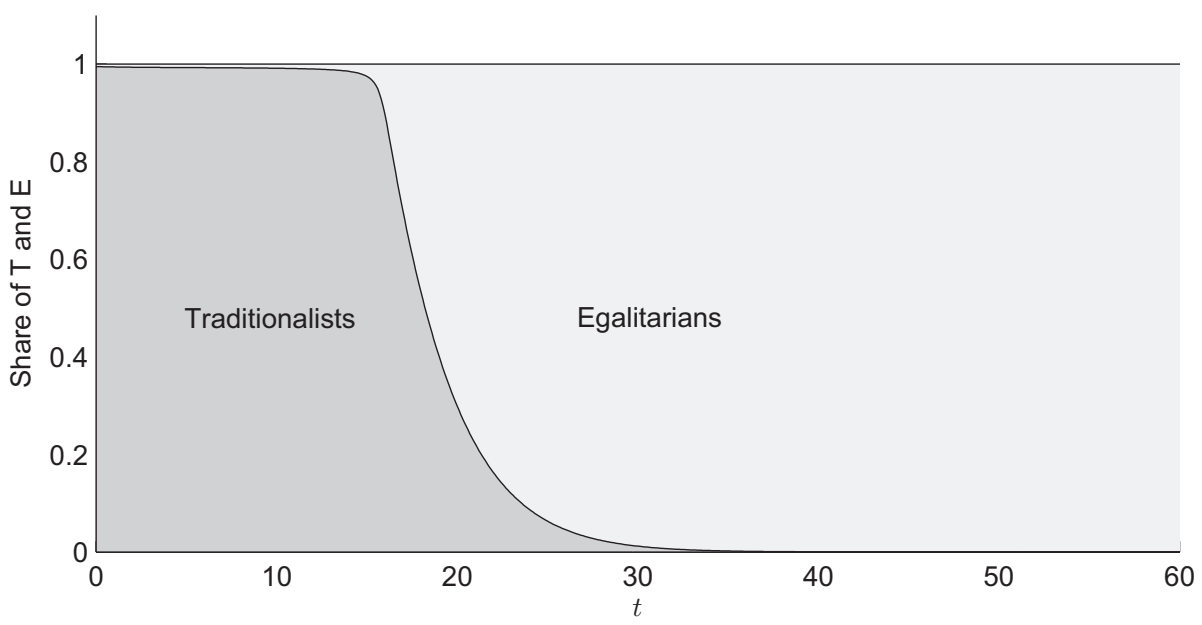

Figure 5: Development of the share of traditionalists and egalitarians within the total population over time for $T_{0}=2, E_{0}=0.01$. 
Figure 5 reveals that for the given parameters, initially the traditionalists dominate society. However, there is a shift from a traditional to an egalitarian society and in the long run egalitarianism prevails.

One of the main drivers for the rebound in fertility can be found in the difference between parameters $m$ and $n$ which denote the steepness of the S-shaped curves describing the impact of social interactions between egalitarians on the birth rates and on the diffusion of family values, respectively. We can see that for the parameters used $m>n$, which means that function $f(E)$ is steeper than $b_{E}(E)$ for small $E$. Such a difference arises when there is a delay between becoming egalitarian and finding support e.g. by policy measures facilitating the combination of this lifestyle and parenthood. For example, it might happen that more and more women reach a higher education level and, consequently, a higher degree of employment. Due to a higher exposure, such women are more likely to adopt an egalitarian lifestyle than women with lower education, see Davis and Greenstein (2009). However, when politics does not react quickly enough to this change of family values, i.e. measures like the possibility of father leaves or the creation of additional child care facilities are only implemented for a higher number of egalitarians, the support within society is not strong enough to keep fertility rates up to the level of a traditional society, and consequently birth rates will fall. A policy maker interested in avoiding a decline in fertility would have to adapt policies in correspondence with the diffusion process.

These findings are confirmed in Figure 6, where we study how birth rates are affected by parameters $m$ and $n$. For our basic parameter set the initial decline in the birth rate is quite steep but the increase after some time is rather flat. The reason for this steep initial decline is that the diffusion process happens rather quickly once started as $T$ is large then. The growing size of $E$ also speeds up the spreading of egalitarian family values. As the impact of the establishment of egalitarianism happens with a delay, birth rates grow more slowly than the initial decrease of the overall birth rate.

The left panel of 6 demonstrates how the decrease in fertility and its subsequent recuperation depend on the values of $m$. If $m$ is small, and thus $b_{E}(E)$ is steep, i.e. the marginal increase of birth rates is larger for small $E$ than if parameter $m$ was large, i.e. measures that make parenthood more attractive take effect in an earlier stage of the diffusion process, thus birth rates will not suffer as much as for a high $m$. We can observe that the following increase in the birth rates happens at a lower speed for a small $\mathrm{m}$.

The impact of parameter $n$ can be observed in the right panel of Figure 6 . Not surprisingly, a high value of $n$ delays the diffusion process, and as the difference between $m$ and $n$ is smaller compared to other scenarios, overall birth rates will not be affected as much by the rise of egalitarianism. That is, both becoming egalitarian and egalitarian parenthood are only attractive if there is already a rather high number of egalitarians. The increase of birth rates becomes less steep with a lower $n$. 

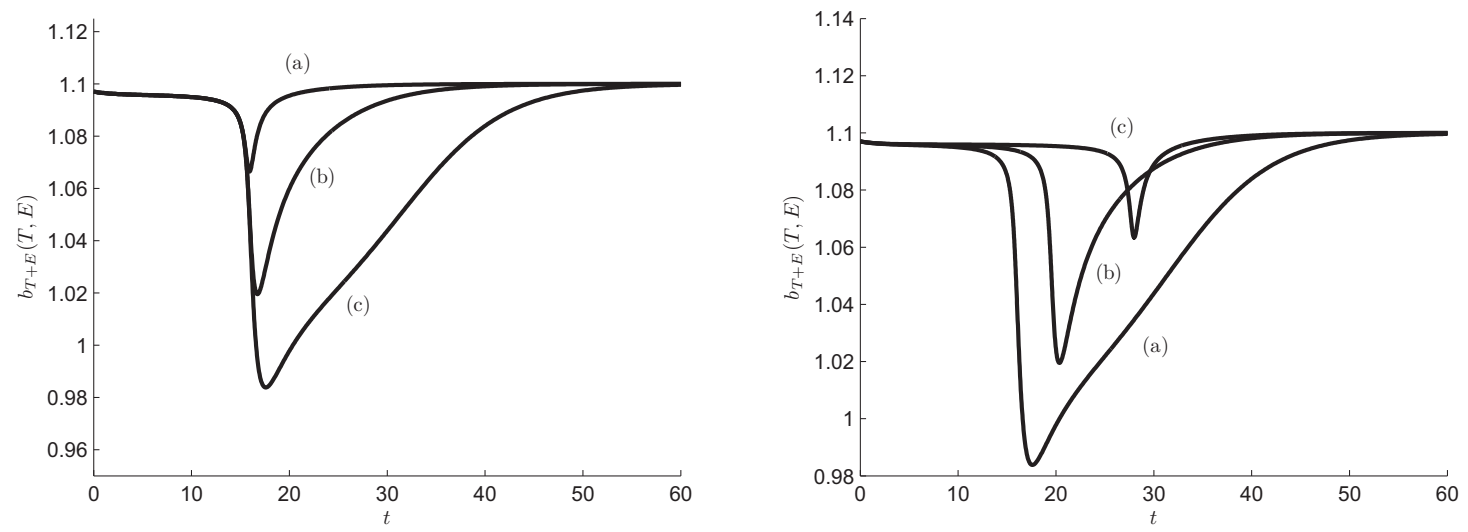

Figure 6: U-shape dependence parameters $m$ (left panel; $n=0.5$ and (a) $m=1$, (b) $m=6$, (c) $m=12$ ) and $n$ (right panel; $m=12$ and(a) $n=0.5$, (b) $n=1$, (c) $n=5$ ) for $T_{0}=2, E_{0}=0.01$.
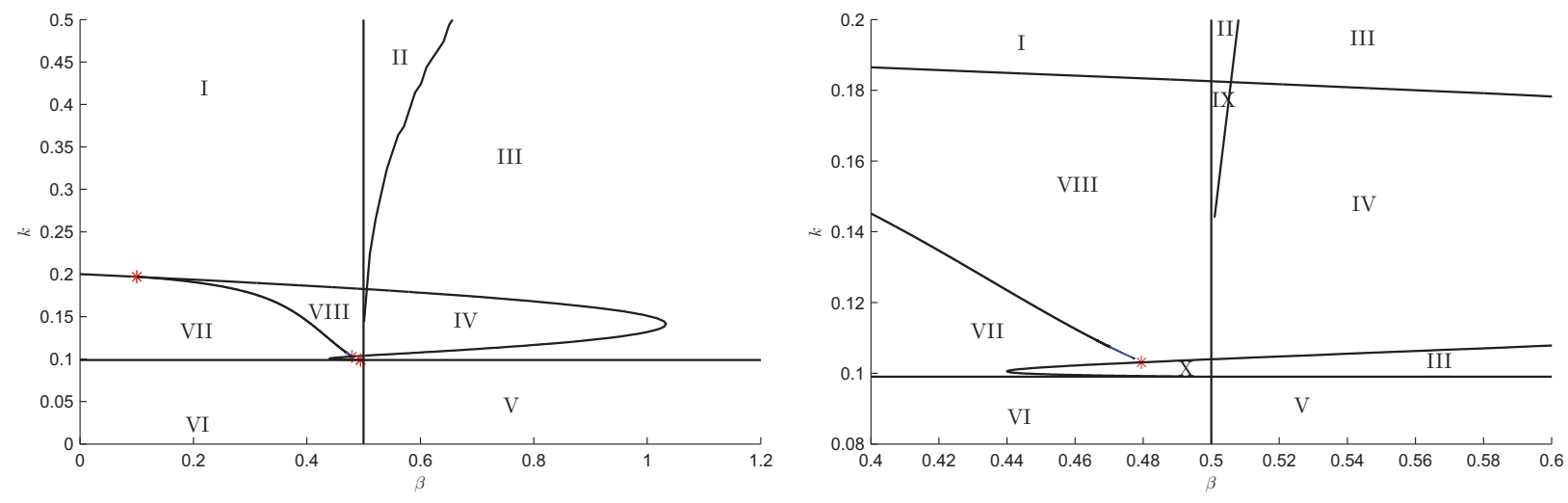

Figure 7: Bifurcation diagram; the right panel is a zooming of the left panel 

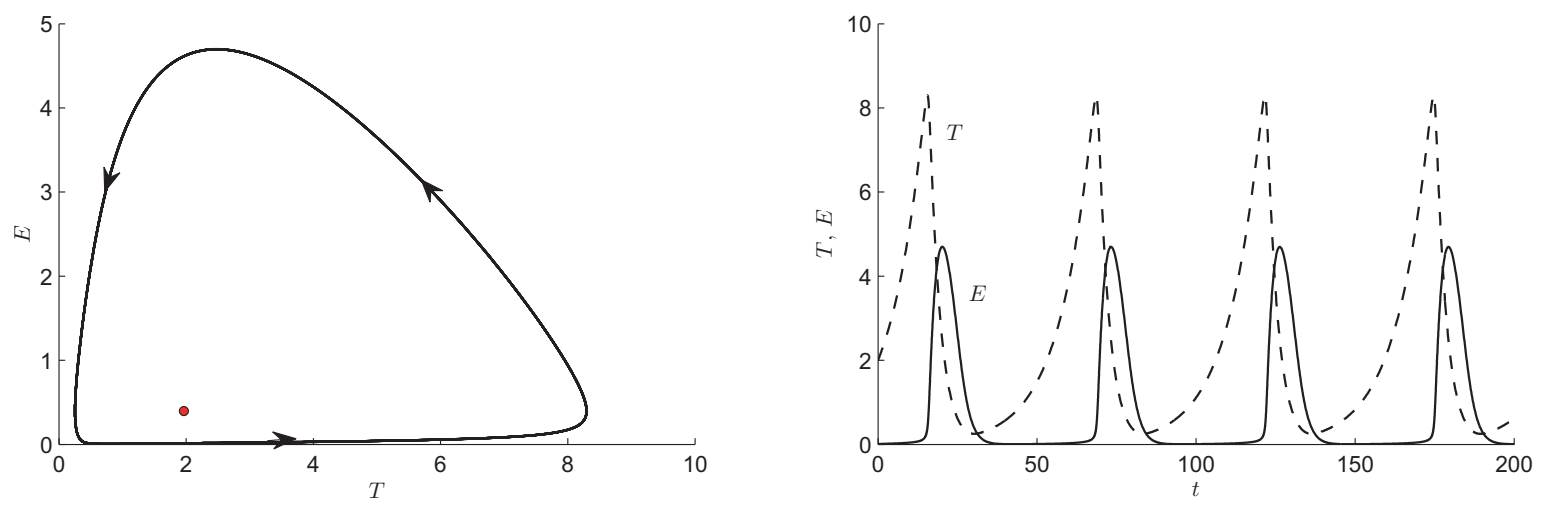

Figure 8: Phase portrait and time path for $k=0.4, \beta=0.45$ (Region I) and $T_{0}=$ $2, E_{0}=0.02$

\subsection{Bifurcation Analysis}

In the following, we conduct an extensive bifurcation analysis for which we use the MATLAB toolbox MATCONT, see e.g. Dhooge et al. (2003). For more details about bifurcation theory, we refer to Guckenheimer and Holmes (1983); Strogatz (1994). We consider two key parameters, namely the pace of diffusion $k$ and the impact of the externality on the birth rate $\beta$. The parameters we use for the numerical calculations are described in Table 1 .

Figure 7 shows the bifurcation diagram, Table 2 contains a brief description of each parameter region. We can see that in the long run egalitarianism will always dominate, except if the pace of diffusion is too fast and the increase of birth rates due to social influences too low. Due to the fast adoption of egalitarian family values, the number of traditionalists will drop. Due to the low impact of social interactions among egalitarians on birth rates, the corresponding decline of fertility rates cannot be compensated quickly enough and either population will reach a constant level or fluctuate in the long run. In the following sections, however, we will see that also the initial number of traditionalists and egalitarians can play an important role on the development of the total population.

\subsubsection{Periodic Population Development}

In Regions I, II, VIII, IX and X, the long-run solution might approach a limit cycle depending on the initial size of $T$ and $E$.

If the initial number of egalitarians is small, the overall population will grow as a consequence of the high birth rate of the traditionalists. Diffusion will start slowly, but after some time $E$ will reach a critical threshold and social pressure for gender equality becomes so strong that traditionalism will decrease and the overall birth rate within a population will decline as well. However, due to their low birth rate which is below the replacement level, the number of egalitarians will also start to decrease after some time. As the flow from $T$ to $E$ becomes very small, the number of traditionalists and the birth 


\begin{tabular}{|c|c|}
\hline Region I & $\begin{array}{l}\text { The interior steady state is an unstable focus, the boundary steady } \\
\text { state }\left(T_{B}, E_{B}\right) \text { is not admissible. There is one stable limit cycle. In the } \\
\text { long run the size of the two groups fluctuates as well as the birth rates. } \\
\text { See Sect. } 4.2 .1 \text { for a detailed interpretation of a periodic solution. }\end{array}$ \\
\hline Region II & $\begin{array}{l}\text { The interior steady state is an unstable focus, both boundary steady } \\
\text { states are saddle points. If } T_{0} \text { or } E_{0} \text { is big the population grows in the } \\
\text { long run, and egalitarianism will dominate after some time. If } T_{0} \text { and } \\
E_{0} \text { are small enough, the solution path approaches a limit cycle. See } \\
\text { Sect. } 4.2 .1 \text {. }\end{array}$ \\
\hline Region III & $\begin{array}{l}\text { The interior steady state is an unstable focus, both boundary steady } \\
\text { states are saddle points. There is no cycle. For a more detailed } \\
\text { description, see Sect. } 4.1 \text {. }\end{array}$ \\
\hline Region IV & $\begin{array}{l}\text { The interior steady state is a stable focus, both boundary steady states } \\
\text { are saddle points. If } T_{0} \text { or } E_{0} \text { is within the unstable cycle, the long-run } \\
\text { population will spiral towards a constant level, i.e. that of the interior } \\
\text { steady state (see Sect. } 4.2 .2 \text { ), where traditionalism will dominate. } \\
\text { Otherwise, the population explodes in the long run and egalitarianism } \\
\text { prevails. See Sect. } 4.2 .3 \text { for more details on history-dependent solution } \\
\text { paths. }\end{array}$ \\
\hline Region V & $\begin{array}{l}\text { Only the boundary steady states are admissible, }\left(\hat{T}_{B}, \hat{E}_{B}\right) \text { is an } \\
\text { unstable node, }\left(\hat{T}_{0}, \hat{E}_{0}\right) \text { is a saddle point. In the long run both } \\
\text { population groups grow, but the growth of egalitarians is stronger; } \\
\text { consequently their family values will dominate the population after } \\
\text { some time, independent of the initial state values. }\end{array}$ \\
\hline Region VI & $\begin{array}{l}\text { Only the boundary steady state }\left(T_{0}, E_{0}\right) \text { is admissible and a saddle } \\
\text { point. In the long run, both the number of egalitarians as well as the } \\
\text { number of traditionalists grows. The size of the total population will } \\
\text { also increase as a result. }\end{array}$ \\
\hline Region VII & $\begin{array}{l}\text { The interior steady state is a stable focus. Independent of the initial } \\
\text { state values one always approaches the steady state, see Sect. } 4.2 .2 \text {. }\end{array}$ \\
\hline Region VIII & $\begin{array}{l}\text { The interior steady state is a stable focus. Furthermore, there is one } \\
\text { unstable cycle and one stable limit cycle. Depending on the initial size } \\
\text { of the two groups, the population either reaches a constant long-run } \\
\text { steady-state level or fluctuates; see Sect. } 4.2 .3 \text {. }\end{array}$ \\
\hline Region IX & $\begin{array}{l}\text { The interior steady state is a stable focus, both boundary steady states } \\
\text { are admissible and saddle points. The solution is history-dependent: if } \\
T_{0} \text { and } E_{0} \text { are small and within the unstable cycle, the population } \\
\text { approaches a steady-state level. Outside, but still for } T_{0} \text { and } E_{0} \text { rather } \\
\text { small, the population groups' sizes fluctuate in the long run. If } T_{0} \text { or } \\
E_{0} \text { is big, the population explodes in the long run. }\end{array}$ \\
\hline Region X & $\begin{array}{l}\text { The interior steady state is an unstable focus, the long-run solution will } \\
\text { always approach a limit cycle, see Sect. 4.2.1. }\end{array}$ \\
\hline
\end{tabular}

Table 2: Regions corresponding to the bifurcation diagram in Figure 7. 

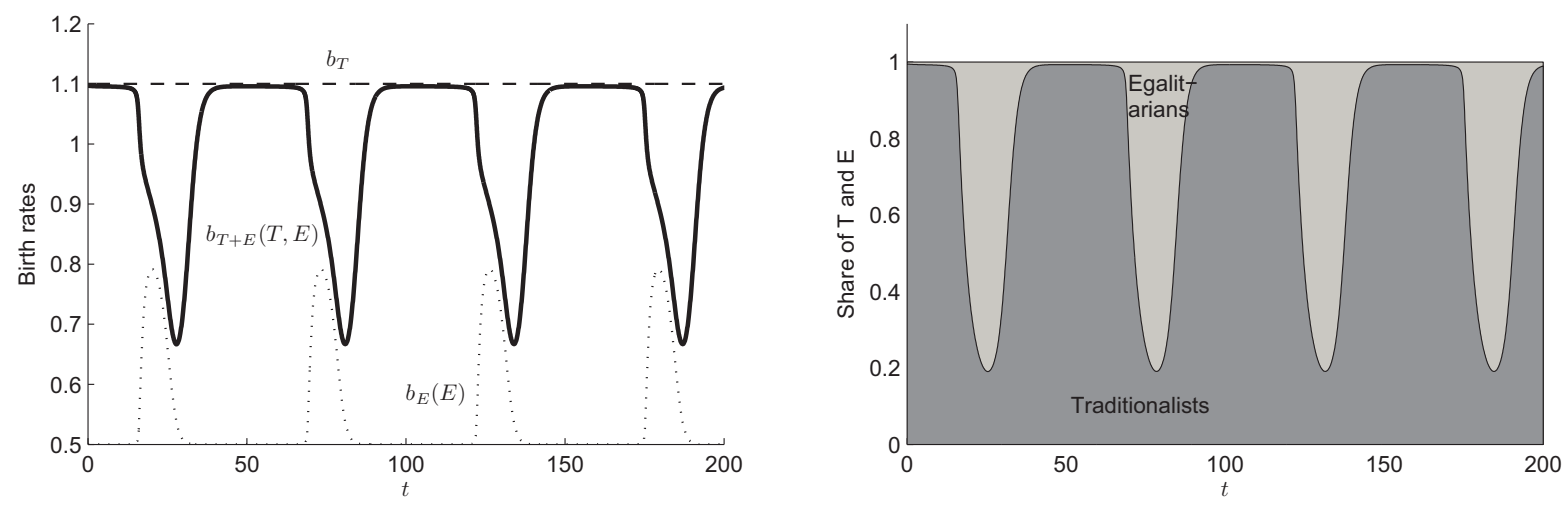

Figure 9: Development of birth rates and share of egalitarians and traditionalists within the total population for $k=0.4, \beta=0.45$ (Region I) and $T_{0}=2, E_{0}=0.02$
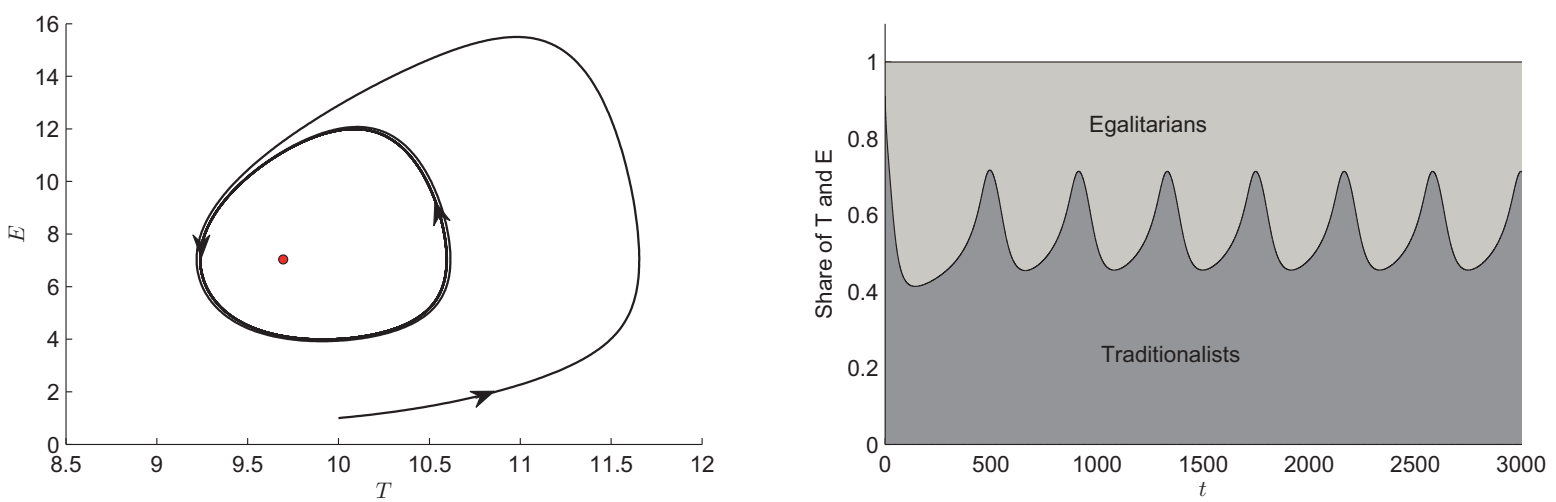

Figure 10: Phase portrait (left panel) and development of the share of egalitarians and traditionalists within the total population (right panel) for $k=0.1, \beta=0.45$ (Region $\mathrm{X}$ ) and $T_{0}=2, E_{0}=0.02$

rate of the total population can recover. See Figure 8 for a phase portrait, time path and Figure 9 for the corresponding development of birth rates and the share of traditionalists and egalitarians within the total population. Note that in this example the egalitarian population gets almost extinct at certain times and the number of traditionalists also becomes rather small. This is due to the large diffusion parameter $k$ and the small impact of egalitarianism on birth rates $\beta$ in Region I: While the traditional population gets easily attracted by egalitarianism, even when many of them join the egalitarian group, this lifestyle does not find enough support measures that facilitate its combination with parenthood. Thus the population size will fall.

In Figure 10 we can see an example where this phenomenon does not occur. Here the speed of diffusion is much smaller, consequently, $T$ will not decline as much and, consequently, there is always sufficient inflow to $E$ so that they will always have a non-neglectible share within the population. As we can see, in this scenario sometimes traditionalism will dominate and sometimes egalitarianism. 

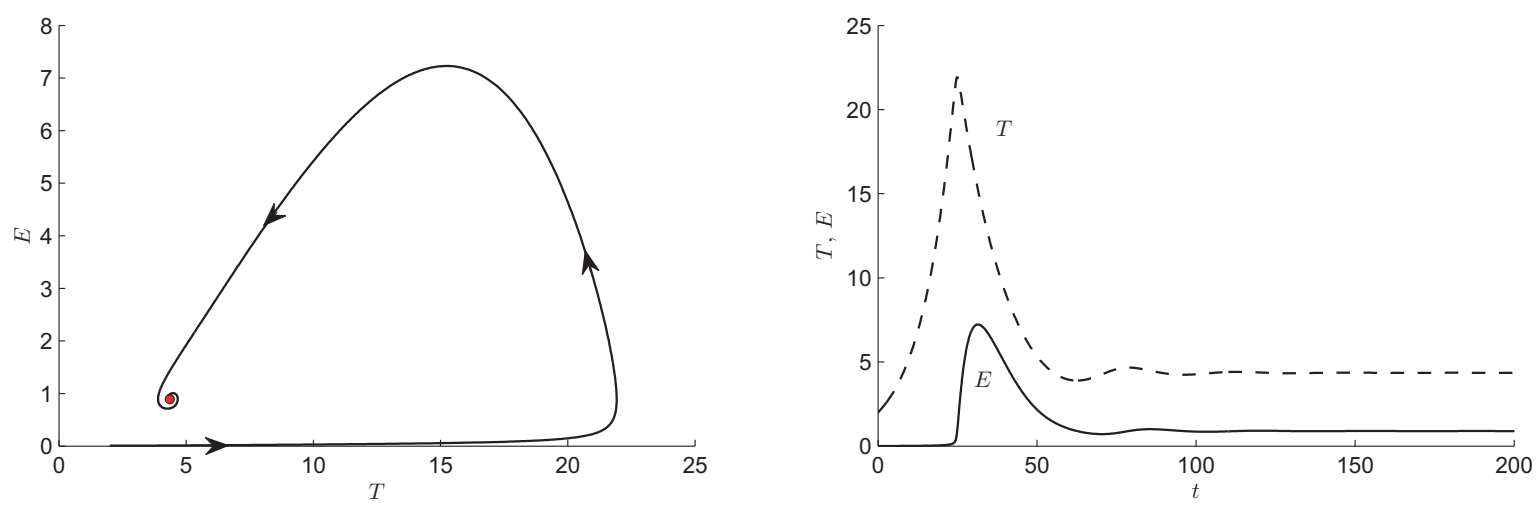

Figure 11: Phase portrait and time path for $k=0.16, \beta=0.2$ (Region VII) and $T_{0}=2, E_{0}=0.02$
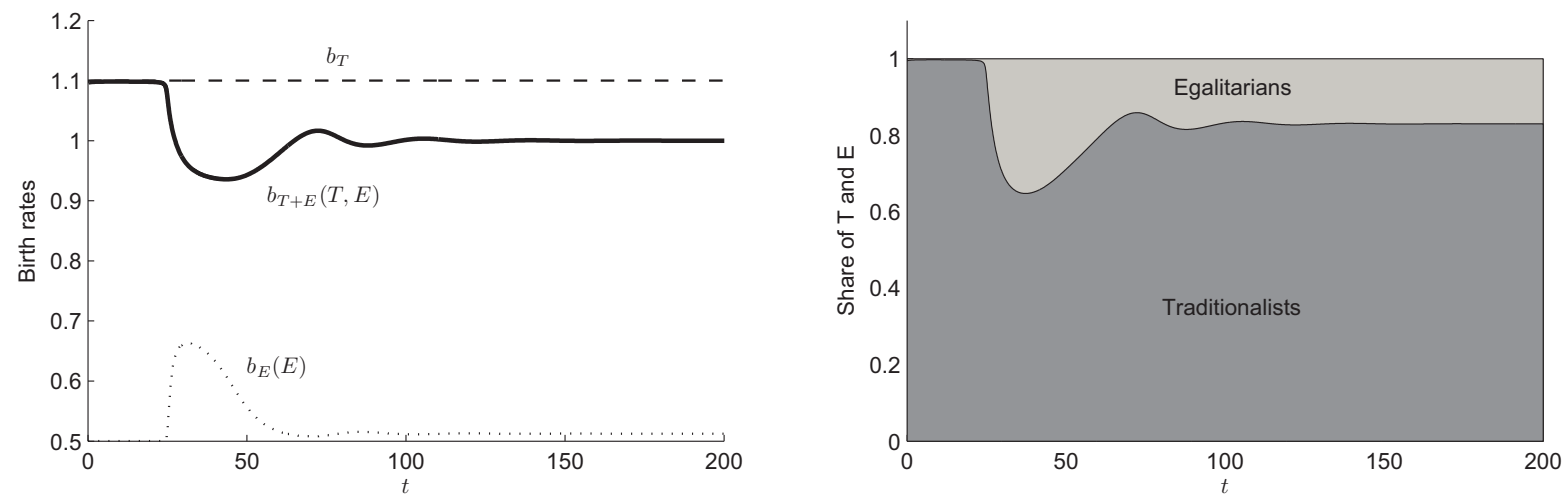

Figure 12: Development of birth rates and share of egalitarians and traditionalists within the total population for $k=0.16, \beta=0.2$ (Region VII) and $T_{0}=2, E_{0}=0.02$ 

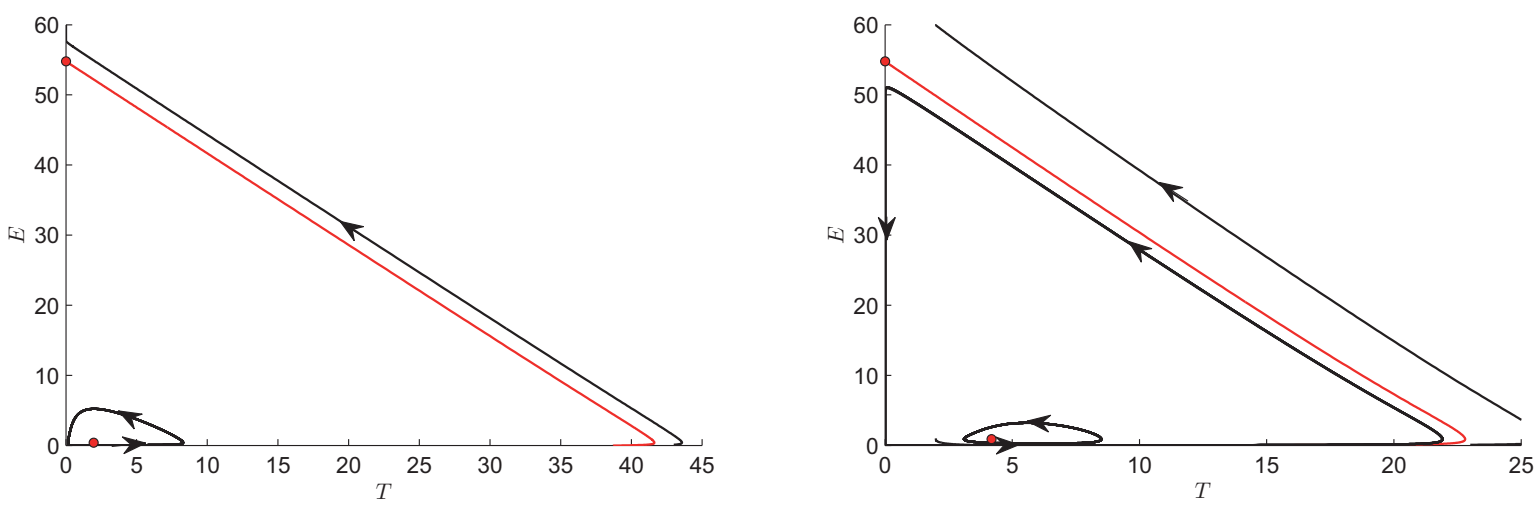

Figure 13: Phase portrait and time path for $k=0.4, \beta=0.502$ (Region II; left panel) and $k=0.16, \beta=0.502$ (Region IX; right panel)

\subsubsection{A Constant Size of the Population in the Long Run}

The population can reach a constant level in Regions IV, VII, VIII and IX, again depending on the initial state values. In Figure 11 we can see an example of how the population will develop in Region VII. Here the initial size of $T$ is again large, while $E_{0}$ is small. However, no matter how big the initial size of the two groups is within this particular parameter region, a constant level will always be reached, even if the sizes of the two groups might first increase or decrease. In Section 3 we were able to see that only the interior steady state is a candidate for a long-run solution (except in the hairline cases when one starts on the one-dimensional stable manifold of one of the boundary steady states). The share of the two population groups in the steady state, see Figure 12, crucially depends on the choice of parameters, however, both population groups will co-exist. Furthermore, due to our assumption that the birth rate of traditionalists is larger than their death rate, the long-run birth rate of egalitarians must be smaller than their death rate, so that the total population size can remain constant in the long run.

It is also possible to observe a U-shaped development of the overall birth rate here: Given a large initial number of traditionalists and a small initial number of egalitarians, birth rates will fall once the diffusion process within society starts. Then the occurrence of the egalitarian family model increases while traditionalism declines. However, in the case depicted in Figures 11 and 12 the U-shape only arises due to a subsequent recovery of the traditional lifestyle and a partial renunciation from egalitarianism, which relates to the comparatively low speed of diffusion as well as the rather small impact of the externality.

\subsubsection{History-Dependent Population Development}

In the two preceding sections we saw that a periodic solution might prevail in Regions I, II, VIII, IX and X and the interior steady state might play an important role for the long run solution in Regions I, II, VIII, IX and X. Furthermore, the population might grow in the long run in Regions II, III, IV, V, VI and IX. Here we can clearly see, that in Regions II, IV, VIII and IX, the long-run behaviour of the solution is clearly history-dependent, 

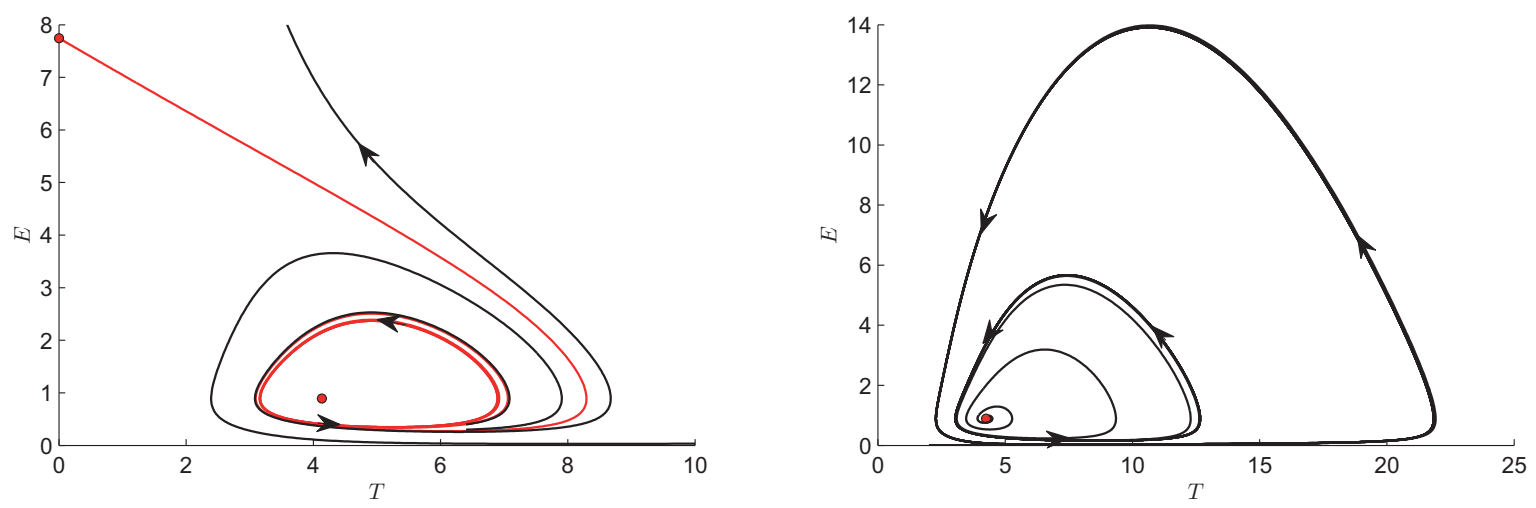

Figure 14: Phase portrait and time path for $k=0.16, \beta=0.2$ (Region IV; left panel) and for $k=0.16, \beta=0.4$ (Region VIII; right panel)

i.e. it depends on the initial size of $T$ and $E$ whether the population is constant, grows or fluctuates in the long run.

Figures 13 and 14 show the phase portrait for the parameter regions where the longrun population development crucially depends on the initial number of egalitarians and traditionalists. See Table 2 for a short description of the potential behaviour of the longrun solution depending on the initial state value. The most interesting case is certainly to be found within Region IX: there is one unstable cycle. If the initial state values lie within this cycle, the population will reach a constant level in the long run. However, if starting outside this unstable cycle and neither the number of traditionalists nor of egalitarians is too big, the solution path will approach a stable limit cycle. If, however, the initial size of $T$ or $E$ is big, the population size will grow in the long run. Interestingly, if approaching the steady state, traditionalism will prevail. If approaching the limit cycle, both lifestyles will alternately dominate. In the case with continuing population growth, egalitarianism will dominate in the long run.

\section{Conclusion \& Extensions}

In the title of the present paper we ask whether egalitarian society boost fertility. The answer to this question, however, is not straightforward as several important factors influence the development of fertility over the course of the transition from a traditional to an egalitarian society. One thing, however, can be said for certain: a decline of fertility due to the establishment of new family values will be stronger the less support in combining parenthood and this lifestyle finds within the population. U-shaped developments of birth rates, as they were observed in several industrialised countries, very much relate to the lag between the diffusion of egalitarian family values and implementation of policy measures that support this lifestyle.

Furthermore, we saw that it is not always clear which family model will dominate in the long run, it very much depends on the underlying parameters such as the speed of diffusion of egalitarian values and the extent to which social interactions influence the 
egalitarians' birth rate. Thus it might happen for certain countries that egalitarianism will not find much support, while in other countries it might even lead to a population growth. Very important here are social interactions, in particular the speed of the impact of diffusion of this relatively new family model.

In an extension we aim to endogenize the birth rate of the traditionalists as well by assuming a negative dependence of the group size $T$ on the corresponding birth rate. The intuition is as follows. Consider $T$ decreasing over time, i.e. former traditionalist families change to egalitarian behaviour. The ones with relatively loose traditionalist behaviour are the first to change. The remaining ones are more strict in the traditionalist role and will have a higher birth rate. As $T$ increases further only true 'extremists' will remain in the $T$ group, which will have the highest birth rate. Similar to $b_{E}$ we assume an S-shape for $b_{T}$. However, in this case the dependence on $T$ is negative. This extension implies different population dynamics with several interior steady states and boundary solutions.

The present model and the above-described extension are descriptive and just a first step. They serve to explain underlying mechanisms related to the spreading of modern family values. For policy makers who are interested in a high birth rate, a high participation of women in the labour marked or just in a high number of votes in the next elections, the model can be extended to the framework of intertemporal optimization. Within such an optimal control problem or dynamic game, the impact of costly policy instruments which promote the more favourable lifestyle and family values, can be studied.

\section{References}

Aassve, A., Billari, F. C., and Pessin, L. (2012). Trust and fertility dynamics. Dondena Working Papers No. 55.

Billari, F. and Kohler, H. (2004). Patterns of low and lowest-low fertility in Europe. Population Studies, 58(2):161-176.

Buber, I. and Neuwirth, N. (2009). Familienentwicklung in Österreich, Erste Ergebnisse des Generations and Gender Survey (GGS). Vienna. http://www.ggpaustria.at/fileadmin/ggp-austria/familienentwicklung.pdf (last accessed, May, 29th, 2013).

Casterline, J. B., editor (2001). Diffusion Processes and Fertility Transition. National Academy Press, Washington, D.C.

Ciabattari, T. (2001). Changes in men's conservative gender ideologies: Cohort and period influences. Gender \& Society, 15(4):574-591.

Conrad, C., Lechner, M., and Werner, W. (1996). East german fertility after unification: Crisis or adaptation? Population and Development Review, 22(2):331-358.

Davis, S. and Greenstein, T. (2009). Gender ideology: Components, predictors, and consequences. Annual Review of Sociology, 35:87-105. 
Dhooge, A., Govaerts, W., and Kuznetsov, Y. (2003). MATCONT: a MATLAB package for numerical bifurcation analysis of ODEs. ACM Transactions on Mathematical Software (TOMS), 29(2):141-164.

Esping-Andersen, G. (2009). The Incomplete Revolution. Polity Press, Cambridge.

Esping-Andersen, G. and Billari, F. C. (2012). Re-theorizing family demographics. Working Paper.

Esping-Andersen, G., Boertien, D., Bonke, J., and Garcia, P. (2012). Couple specialization in multiple equilibria. Working Paper.

Grass, D., Caulkins, J. P., Feichtinger, G., Tragler, G., and Behrens, D. A. (2008). Optimal Control of Nonlinear Processes: With Applications in Drugs, Corruption and Terror. Springer, Heidelberg.

Guckenheimer, J. and Holmes, P. (1983). Nonlinear oscillations, dynamical systems, and bifurcations of vector fields, volume 42. Springer, New York.

Lopez-Pintado, D. and Watts, D. (2008). Social influence, binary decisions and collective dynamics. Rationality and Society, 20(4):399-443.

McDonald, P. (2000). Gender equity in theories of fertility transition. Population and Development Reviewe, 26(3):427-439.

McDonald, P. (2013). Societal foundations for explaining low fertility: Gender equity. Demographic Research, 28(34):981-994.

Myrskylä, M., Kohler, H. P., and Billari, F. C. (2009). Advances in development reverse fertility declines. Nature, 460(7256):741-743.

Rogers, E. (2003). Diffusion of Innovations. Free Press, 5th edition edition.

Strogatz, S. H. (1994). Nonlinear dynamics and Chaos: With applications to physics, biology, chemistry, and engineering. Addison-Wesley, Reading, MA.

Torr, B. M. and Short, S. E. (2004). Second births and the second shift: A research note on gender equity and fertility. Population and Development Reviewe, 30(1):109-130. 


\section{VIENNA INSTITUTE OF DEMOGRAPHY}

\section{Working Papers}

Muttarak, Raya, Is it (dis)Advantageous to Have Mixed Parentage? Exploring Education \& Work Characteristics of Children of Interethnic Unions in Britain?, VID Working Paper 01/2013.

Testa, Maria Rita and Stuart Basten, Have Lifetime Fertility Intentions Declined During the "Great Recession"?, VID Working Paper 09/2012.

Buber, Isabella, Ralina Panova, and Jürgen Dorbritz, Fertility Intentions of Highly Educated Men and Women and the Rush Hour of Life, VID Working Paper 08/2012.

Testa, Maria Rita, Laura Cavalli, and Alessandro Rosina, The Decision of Whether to Have a Child: Does Couple Disagreement Matter?, VID Working Paper 07/2012.

Kuhn, Michael and Klaus Prettner, Growth and Welfare Effects of Health Care in Knowledge Based Economies, VID Working Paper 06/2012.

Sander, Nikola and Martin Bell, Age, Period and Cohort Effects on Migration of the Baby Boomers in Australia, VID Working Paper 05/2012.

Grafeneder-Weissteiner, Theresa, Ingrid Kubin, Klaus Prettner, Alexia Prskawetz, and Stefan Wrzaczek, Coping with Inefficiencies in a New Economic Geography Model, VID Working Paper 04/2012.

Goujon, Anne, Éric Caron Malenfant, and Vegard Skirbekk, Towards a Catholic North America? Projections of Religion in Canada and the US beyond the Mid-21st Century, VID Working Paper 03/2012.

Di Giulio, Paola, Christoph Bühler, Andreas Ette, Romina Fraboni, and Kerstin Ruckdeschel, Social Capital and Fertility Intentions: The Case of Italy, Bulgaria, and West Germany, VID Working Paper 02/2012.

Abel, Guy J., Estimating Global Migration Flow Tables Using Place of Birth Data, VID Working Paper 01/2012.

Ediev, Dalkhat M., At Modal Age at Death, the Hazard Rate is Determined by its Derivative, VID Working Paper 08/2011.

Zeman, Kryštof, Tomáš Sobotka, Richard Gisser, Maria Winkler-Dworak, and Wolfgang Lutz, Geburtenbarometer Vienna: Analysing Fertility Convergence between Vienna and Austria, VID Working Paper 07/2011 (English and German versions available).

The Vienna Institute of Demography Working Paper Series receives only limited review. Views or opinions expressed herein are entirely those of the authors. 